\title{
Late ocular changes after closantel poisoning in five women
}

\author{
Rimvydas Asoklis $^{1} \cdot$ Andrius Cimbalas $^{1} \cdot$ Aiste Augyte $^{1} \cdot$ Ernesta Jasinskiene $^{1} \cdot$ Rasa Strupaite $^{1}$
}

Received: 30 May 2018 / Accepted: 5 June 2018 / Published online: 3 August 2018

(c) The Royal College of Ophthalmologists 2018

\section{Introduction}

In 1993, donated closantel (Fukiver) was mistakenly administered by a gynecologist to eleven female patients in Lithuania, for use as a treatment for endometritis [1].

Closantel is a salicylanilide-derived compound commonly used as an anthelmintic in veterinary practice [2]. In literature we found only few cases of closantel poisoning in humans, but no cases of late ocular changes were found [3-5]. Therefore, the aim of this article is to assess late ocular changes after closantel poisoning in humans.

\section{Material and methods}

Seven patients received closantel in different dosages and durations; the remaining four patients were suspicious about the tablet size and refused to take it. Twentytwo years after the poisoning we reexamined five of these patients; the remaining two were absent. We performed visual field evaluation by Goldmann kinetic perimeter (Carl Zeiss, Jena, Germany), fundus photographs, retina examination by spectral domain optical coherence tomography (SD-OCT) (Heidelberg Engineering $\mathrm{GmbH}$, Heidelberg, Germany) and electroretinography by retiport gamma plus (Roland Consult, Brandenburg, Germany).

The study conformed to the tenets of the 1975 Declaration of Helsinki, ethical approval from the Institutional Review Board at Vilnius University was received.

Rimvydas Asoklis

rimvydas.asoklis@santa.lt

1 Vilnius University, Department of Ear, Nose, Throat and Eye, Centre of Eye Diseases, Vilnius, Lithuania

\section{Results}

Summarized information of five patients showing age, symptoms, intake time, time after symptoms presentation, and best-corrected visual acuity (BCVA) at presentation and after 22 years is presented in Table 1.

Deterioration of visual field, changes in the fundus and irregularity of retinal layers in all five women are shown in Fig. 1.

Electroretinography revealed reduced visual evoked potential amplitudes with delayed peak latencies in all eyes.

\section{Discussion}

A histological study of animals' eyes after closantel intoxication showed edema in the intracanalicular portion of the optic nerve, which is in the osseous part, therefore, optic nerve is compressed, resulting loss of myelinated axons [2].

In the present cases, the visual acuity improved in three affected women and decreased in two, compared to the initial examination. In other known cases of closantel poisoning, the visual acuity recovered only partially, also blindness case was recently reported [3-5].

In our cases visual fields were markedly constricted in four of five women and deterioration of visual field defects over time was observed. Given the lack of longterm observations, we cannot exclude the possibility that the visual field deterioration represents the progression of closantel poisoning.

Animal studies have shown that damage to the retina leads to thinning of the outer layers, particularly the photoreceptive cells [2]. In SD-OCT we also observed irregular and thinner retinal pigment epithelium, photoreceptor, outer nuclear, outer plexiform, and inner nuclear retinal layers, compared to healthy adults. These anatomical changes results dysfunction of the retina, that is presented in the electroretinography. Furthermore, fundus findings agree with histological studies of cattle, which 
Table 1 Summarized medical information of five patients

\begin{tabular}{|c|c|c|c|c|c|c|c|c|c|}
\hline \multirow{2}{*}{$\begin{array}{l}\text { Case } \\
\text { no. }\end{array}$} & \multirow{2}{*}{$\begin{array}{l}\text { Age at } \\
\text { presentation }\end{array}$} & \multirow[t]{2}{*}{ Symptoms } & \multirow{2}{*}{$\begin{array}{l}\text { Closantel } \\
\left.\text { intake (q.d. }{ }^{a}\right)\end{array}$} & \multirow{2}{*}{$\begin{array}{l}\text { Time of symptoms } \\
\text { presentation (after } \\
\text { last tab. intake) (day) }\end{array}$} & \multirow{2}{*}{$\begin{array}{l}\text { Hospitalisation time } \\
\text { after ocular symptoms }\end{array}$} & \multicolumn{2}{|c|}{$\mathrm{BCVA}^{\mathrm{b}}$ in 1993} & \multicolumn{2}{|c|}{ BCVA in 2015} \\
\hline & & & & & & OD & OS & OD & OS \\
\hline 1 & 28 & $\begin{array}{l}\text { Blurred vision, } \\
\text { photopsias }\end{array}$ & $3 \mathrm{tab}^{\mathrm{c}}$ & 2 & 1 week & $20 / 250$ & $20 / 250$ & $20 / 63$ & $20 / 200$ \\
\hline 2 & 22 & $\begin{array}{l}\text { Haze and black } \\
\text { spots }\end{array}$ & 3 tab. & 3 & 3 days & $20 / 32$ & $20 / 63$ & $20 / 25$ & $20 / 40$ \\
\hline 3 & 25 & $\begin{array}{l}\text { Visual decrease, } \\
\text { blurred vision }\end{array}$ & 3 tab. & 1 & 5 days & $20 / 32$ & $20 / 20$ & $20 / 20$ & $20 / 20$ \\
\hline 4 & 38 & Blurred vision & 3 tab. & 1 & 1 day & $20 / 20$ & $20 / 20$ & $20 / 40$ & $20 / 40$ \\
\hline 5 & 24 & Photopsias & 3.5 tab. & 1 & 3 days & $20 / 20$ & $20 / 20$ & $20 / 25$ & $20 / 25$ \\
\hline
\end{tabular}

${ }^{\mathrm{a} O n c e}$ a day

${ }^{\mathrm{b}}$ Best-corrected visual acuity

${ }^{\mathrm{c}}$ Tablets

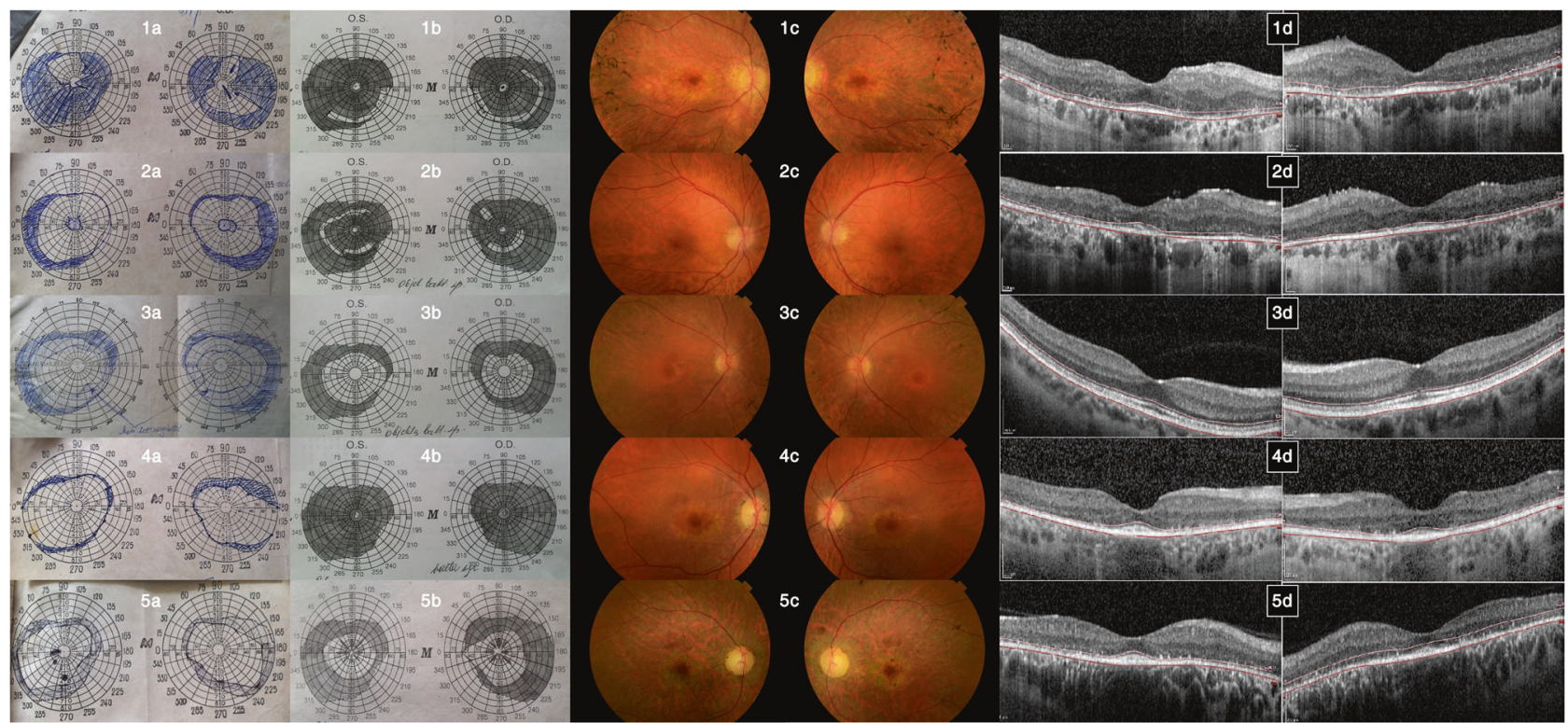

Fig. 1 Goldmann visual fields in 1993 - A and 22 years after - B; fundus photographies (A - right eye, B - left eye) and SD-OCT macular images (A - right eye, B - left eye) of the five patients. Goldmann Visual Fields show progression of bilateral constriction and paracentral scotomas. Fundus photographies reveal irregular macula,

show that closantel poisoning causes damage to the retinal pigment epithelium, resulting spicule-like hyperpigmentation [2].

To conclude, 22 years after poisoning, changes in visual acuity were partially reversible, however, visual-field defects worsened over time and changes in the fundus, retinal thinning were observed. These results demonstrate long lasting negative effect to the retina, with no significant recovery over 22 years.

Acknowledgements The authors would like to thank MD Ramute Ona Kadziene for referring patients for examination. optic disc atrophy, retinal arteriolar attenuation and bone spicule-like pigmentary lesions in midperiphery. SD-OCT macular images reveal thinning of retinal pigment epithelium and disturbance of ellipsoid zone (IS/OS junction)

\section{Compliance with ethical standards}

Conflict of interest The authors declare that they have no conflict of interest.

\section{References}

1. Hoen E, Hodgkin C, Milkevicius D. Harmful human use of donated veterinary drug. Lancet. 1993;342:308-9.

2. Van der Lugta JJ, Venter I. Myelin vacuolation, optic neuropathy and retinal degeneration after closantel overdosage in sheep and in a goat. J Comp Pathol. 2007;136:87-95. https://doi.org/10.1016/j. jcpa.2006.11.007. 
3. Koziolek MJ, Patschan D, Desel H, Wallbach M, Callizo J. Closantel poisoning treated with plasma exchange. JAMA Ophthalmol. 2015;133:718-20. https://doi.org/10.1001/jamaophthalmol.2015. 191

4. Essabar L, Meskini T, Ettair S, Erreimi N, Mouane N. Harmful use of veterinary drug: blindness following closantel poisoning in a 5-year-old girl. APJMT . 2014;3:173-75. https://doi.org/10.22038/ APJMT.2014.3486.

5. Tabatabaei SA, Soleimani M, Mansouri MR, Mirshahi A, Inanlou B, Abrishami M, et al. Closantel; a veterinary drug with potential severe morbidity in humans. BMC Ophthalmol. 2016;16:207 https://doi.org/10.1186/s12886-016-0387-x. 